\title{
Evolución del informativo audiovisual en opinión de sus creadores: de la televisión a la carta al vodcasting
}

\author{
The evolution of audiovisual news in the opinion of its creators: \\ from on-demand television to vodcasting
}

\author{
Moreno-Espinosa, P., Román-San Miguel, A. y Flores-Vivar, J. M. ${ }^{1}$ \\ Recibido: 14-05-2021 - Aceptado: 15-08-2021 \\ https://doi.org/10.26441/RC20.2-2021-A16
}

RESUMEN: Si hasta ahora los informativos habían sido pensados para su difusión a través de grandes formatos de pantalla, sobre todo pantallas de televisión y ordenador, desde hace una década, los programadores se han esforzado por llegar a los consumidores de formatos más reducidos de receptores como las tabletas y, más recientemente, los teléfonos móviles. Ante dicha realidad, los informativos en televisión se han ido redefiniendo y reorientando, utilizando incluso imágenes no profesionales para su difusión. En este artículo, se hace un repaso de la evolución del informativo audiovisual, del informativo en televisión a la televisión a la carta y de ahí, su paso al vodcasting; todo ello a través de una bibliografía actualizada y la visión de los directivos de informativos en televisión. Hacemos uso, por tanto, de una metodología cualitativa, descriptiva y exploratoria aplicando como herramienta metodológica el cuestionario. La información audiovisual ha sido siempre la más consumida y se ha incrementado con situaciones como la pandemia mundial de la enfermedad COVID-19. Según el informe de la consultora Barlovento Comunicación publicado en junio de 2020, el consumo audiovisual en España creció un $22 \%$, tanto a través de la televisión convencional como de Internet. La gestión de la sobreinformación y su adaptación a los nuevos entornos de consumo debe ser una máxima para los gestores de contenidos periodísticos. Nuestro estudio concluye, entre otras cosas, que aunque las formas de consumo han variado considerablemente y los directivos de informativos en televisión creen que éstos deben adaptarse a ellas, hasta el momento se han adaptado contenidos a esos nuevos formatos, pero se produce poco material expresamente para las plataformas de podcasting de vídeo o vodcasting en nuestro país.

Palabras clave: Televisión; multiplataforma; vodcasting; narrativas-audiovisuales.

ABSTRACT: While until now news programmes have been designed to be broadcast on large screen formats, especially television and computer screens, for the last decade, programmers have been making efforts to reach consumers on smaller receiver formats such as tablets and, more recently, mobile phones. Faced with this reality, television news has been redefined and reoriented, even using non-professional images for broadcasting. In this article, we review the evolution of audiovisual news, from television news to on-demand television and from there, its transition to vodcasting; all of this through an updated bibliography and the vision of television news managers. We therefore use a qualitative, descriptive and exploratory methodology, applying a questionnaire as a methodological tool. Audiovisual

\footnotetext{
${ }^{1}$ Pastora Moreno-Espinosa es Doctora en Comunicación y Profesora de las asignaturas Redacción periodística, Principios de Comunicación Institucional y Política, Gestión de la Comunicación Institucional y Política en la Facultad de Comunicación de la Universidad de Sevilla. pamoreno@us.es, https://orcid.org/0000-0001-6494-130X

Aránzazu Román-San Miguel es Doctora en Comunicación y Profesora de las asignaturas Redacción Periodística y Géneros y Estilos Periodísticos Política en la Facultad de Comunicación de la Universidad de Sevilla. arantxa@us.es, https://orcid.org/0000-0002-9131-2629

Jesús Miguel Flores-Vivar es Doctor en Periodismo y Profesor de las asignaturas Multimedia, Ciberperiodismo, Radio Multimedia, Modelos de negocio con tecnologías emergentes en la Facultad de Ciencias de la Información de la Universidad Complutense de Madrid. jmflores@ucm.es, https://orcid.org/0000-0003-1849-5315
} 
information has always been the most consumed and has increased with situations such as the global pandemic of the COVID-19 disease. According to a report by the Barlovento Comunicación consultancy published in June 2020, audiovisual consumption in Spain grew by $22 \%$, both through conventional television and the Internet. The management of over-information and its adaptation to new consumption environments must be a maxim for journalistic content managers. Our study concludes, among other things, that although the forms of consumption have changed considerably and television news managers believe that they must adapt to them, so far content has been adapted to these new formats, but little material is produced expressly for video podcasting or vodcasting platforms in our country.

Key words: TV; multi platform; vodcasting; narrative-audiovisual.

\section{Introducción}

Los hábitos de consumo informativo están cambiando y los jóvenes son el termómetro de hacia dónde nos lleva esta tendencia hoy y hacia el futuro. La población joven tiende a consumir información a través de varias plataformas a la vez, por su capacidad para la multitarea (Casero-Ripollés, 2012, p. 5), de forma que el consumo de información se ha fragmentado. Por este motivo, los contenidos periodísticos tienen que adaptarse a las nuevas formas de consumo.

Internet y la telefonía móvil llevan una década destacando como "dos plataformas muy atractivas para distribuir contenidos audiovisuales". Por un lado, porque permiten a la audiencia "una mayor participación y un uso a la carta" y por otro, implica para "productores y emisores nuevas oportunidades de negocio". En este contexto, si las cadenas de televisión quieren tener "una clientela fija en el futuro van a tener que innovar en contenidos y desarrollar fórmulas nuevas, si no lo van a tener muy complicado" (Ruano, 2009, p. 5).

Conseguir estos objetivos implica superar retos porque, según los expertos, no se ha cumplido la previsión de que la televisión quedaría para "adultos y niños" (Ruano, 2009, p. 7). Actualmente, ni los unos ni los otros son fieles consumidores de la televisión, aunque no se hallan estudios respecto a los niños, porque estudios como el EGM (Estudio General de Medios) empiezan a testar desde los 14 años (Tabla 1). En la franja de edad más joven que recoge el EGM de 2019 (con datos de 2018), Internet supera en visualización a la televisión. De hecho, solo a partir de los 55 años, el uso de la televisión empieza a despuntar por encima del consumo de Internet.

Tabla 1. Penetración de los medios en España-2018-2021 en tanto por ciento

\begin{tabular}{|l|r|r|r|l|}
\hline \multicolumn{1}{|c|}{ EDAD } & \multicolumn{2}{|c|}{ TELEVISIÓN } & \multicolumn{2}{c|}{ INTERNET } \\
& 2018 & 2021 & 2018 & 2021 \\
\hline 14 a 19 & 78.1 & 74.5 & 96.2 & 97 \\
\hline 20 a 24 & 76.9 & 73.4 & 97.8 & 97.5 \\
\hline 25 a 34 & 78.6 & 73.4 & 96.8 & 98 \\
\hline 35 a 44 & 81.7 & 78.1 & 94.1 & 95.9 \\
\hline 45 a 54 & 86.1 & 83.1 & 87.7 & 93.5 \\
\hline 55 a 64 & 88.8 & 88.6 & 75.9 & 87.5 \\
\hline 65 a 74 & 92.3 & 91.8 & 35.8 & 65.4 \\
\hline 75 y más & & 0.4 & & 34.2 \\
\hline
\end{tabular}

Fuente: EGM 2019/AIMC 2021 
El concepto de televisión está cambiando, tanto es así que, según datos del Instituto Nacional de Estadística (INE) de 2018, el 99.1\% de los hogares posee un aparato de televisión y dispone de más de un dispositivo conectado a Internet por donde recibe información audiovisual. De hecho, según este organismo, el número de hogares que posee un ordenador ha ido en aumento, en 2018 era el $79.5 \%$, en 2019 el $80.9 \%$ y en 2020 ya ascendía al $81.4 \%$ de los hogares. El acceso a Internet también se ha incrementado, en este momento el $95.4 \%$ de los hogares posee acceso a la red y el $93.2 \%$ de la población entre 16 y 74 años navega por Internet (INE, 2020). De hecho, en la última década, desde 2010 a 2020 la tasa de hogares con acceso a Internet en España se ha incrementado casi un $40 \%$, desde el $97.8 \%$ de 2010 al $95.4 \%$ en 2020 . Otro dato importante es el número de hogares que tienen conexión a Internet a través del receptor de televisión. De acuerdo al portal Statista, en 2018 el $23.8 \%$ de los hogares disponía de un Smart TV conectado a la red y según el INE en 2020 esta cifra asciende al $66.4 \%$ en la franja de edad entre 16 y 74 años.

Como ha ido ocurriendo con todos los nuevos dispositivos, los precios han ido marcando la evolución del consumo. Las Smart TV llegaron a alcanzar precios muy elevados en su lanzamiento, precisamente, cuando muchas familias hacía poco tiempo que habían adquirido aparatos de televisión HD aún no amortizados. Poco a poco han ido bajando los precios y los usuarios, en unos casos, se han decidido por adquirir una Smart TV y, en otros, han instalado adaptadores para poder acceder a los servicios que ésta permite.

En este contexto de cambio de consumo tan pronunciado (McCarthy, 2020; Bergström et al., 2019; Jiménez-Marín et al., 2018; Doyle, 2016; D’heer y Courtois, 2014), resulta cuanto menos interesante analizar la transformación que han sufrido los informativos en televisión los últimos años y hacia dónde va la información en este sector. Nuevos formatos, nuevas formas de hacer periodismo y nuevas formas de consumo se unen en el futuro de la información periodística audiovisual avizorándose un panorama distinto al ya conocido ecosistema de video y audio. Como sostienen Xosé López-García y Ángel Vizoso (2021), "la tecnología" es "esa arma de doble filo para el periodismo" que "no sólo ha llegado para quedarse, sino que cada vez gana más protagonismo en esta actividad profesional" (p. 9). Se trata de un nuevo escenario en el que los medios y los profesionales tendrán que adaptarse para no quedarse atrás en esta carrera de fondo en la que se encuentra sumergida la industria de la comunicación en su conjunto y, por consiguiente, los productos informativos.

El presente artículo aborda el proceso evolutivo de los informativos en televisión, analizando de dónde vienen y hacia dónde van y la necesidad de adaptarse a los nuevos formatos como los vodcast, que van surgiendo motivados por las nuevas formas de consumo.

\section{Metodología}

El objeto de estudio de este artículo radica en conocer cómo han evolucionado los informativos en televisión y qué opinan los directivos de las cadenas públicas al respecto. Partiendo de la hipótesis de que los informativos en televisión están innovando poco en el entorno multiplataforma, fundamentada en que no es frecuente encontrar en las páginas web de los informativos en televisión productos nuevos, el objetivo principal de este trabajo reside en estudiar si las nuevas formas de consumo de los informativos en televisión han dado lugar a un nuevo formato, el vodcast, con características propias o, por el contrario, todavía hoy se sigue recurriendo a la simple adaptación de la información tradicional, dándose más el informativo a la carta que el vodcast informativo como nuevo formato.

La metodología utilizada es cualitativa y descriptiva. Para la descripción se realiza un repaso bibliográfico acerca del vodcast como objeto de estudio, si bien debemos advertir que, a diferencia de lo que ocurre con el podcasting, sobre el que se ha investigado algo (Legorburu et al., 2021; Moreno 
y Román, 2020; García-Marín, 2019; Moreno, 2017), en el caso del vodcasting la mayoría de la bibliografía hace referencia a su uso en el ámbito docente (Dupagne y Grinfeder, 2009; Cann, 2007; Pagadigorria et al., 2017; Parson et al., 2009), así como algún manual práctico (Geoghegan y Klass, 2007; Brown y Green, 2007), pero no hay referencias de su uso en el ámbito informativo, a pesar de existir ya algunas experiencias incipientes en este sentido.

Para la parte cualitativa, se utilizó la técnica del cuestionario como instrumento. Dicho instrumento fue sometido a la validez de contenido a través de juicio de expertos y en el contexto y terreno de su aplicación. Estuvo dirigido, fundamentalmente, al público responsable de las secciones, áreas o direcciones de los informativos de los medios de televisión españoles, concretamente directivos de TVE en Andalucía y directivos de las diferentes delegaciones de Canal Sur Televisión en la comunidad andaluza. Su utilización tiene como objetivo testar la opinión de los directivos y responsables de informativos acerca de la evolución de los contenidos informativos en los medios audiovisuales, toda vez que Internet y las redes sociales se han ido abriendo paso y cambiando las formas de consumo de información.

El cuestionario, que se envió a través del correo electrónico de forma personal, consta de 12 preguntas abiertas, tales como indicación de: Sexo, Edad, Medio en el que trabaja, Responsabilidad o Puesto dentro de la redacción. Preguntas centradas en la protección de datos (¿Podemos usar su nombre en las respuestas o prefiere mantenerse en el anonimato?). Enfoques y perspectivas (¿Hacia dónde cree que va el periodismo audiovisual en la actualidad?). Centrados también en el proceso de los programas informativos (¿Cuál cree que será el papel del/la periodista en un futuro próximo: 2-3 años?, ¿A largo plazo?); de infraestructura tecnológica y nuevas narrativas (¿Qué papel juega y jugará Internet en el ámbito de los informativos audiovisuales? Respecto a la información audiovisual en los nuevos entornos de consumo, teléfonos y tabletas, ¿cree que se impone una nueva forma de narrar la información, ¿Se han redefinido y orientado los informativos en el paso de los grandes formatos a los de reducido tamaño (tabletas y teléfonos móviles)?, ¿Cómo cree que afecta el entorno multiplataforma a la creación y difusión de información audiovisual?); Definición de los perfiles profesionales (Beneficios y limitaciones del MOJO (mobile journalism) en los informativos audiovisuales) y otras consideraciones. El total de personas encuestadas asciende a 10, dos directivos de TVE de la delegación en Andalucía y 8 directivos de Canal Sur Televisión. Si bien, por deseo expreso de la mayoría de ellos de permanecer en el anonimato no aportamos más datos que los que aparecen en los resultados de este estudio.

\section{Marco referencial: del informativo en televisión a la televisión a la carta}

La llegada de la televisión supuso una gran revolución en el ámbito del periodismo. Dicho medio que permitía informar, formar y entretener con imágenes en movimiento y sonido, hacía más atractivas las formas de consumo de información entre la población. Desde octubre de 1956 en que RTVE comenzara sus emisiones, con la primera cadena (TVE 1), hasta la televisión actual, el entorno de la televisión se ha convertido en el preferido del público, acaparando los contratos más altos en publicidad y unas tasas de audiencia que solo en algunos casos ha podido ser alcanzada por el medio radio. De hecho, en 2020 se ha batido el récord de consumo de televisión debido a la pandemia provocada por el COVID-19. Según publicaba el diario Expansión, el consumo de televisión batió un récord histórico en la primera semana de confinamiento (Juste y Galera, 2020).

Pero esto no siempre fue así, de hecho, Manuel Palacio (2006) sobre los inicios de la televisión sostiene que, en aquellos años, el medio tenía unos "bajísimos niveles de penetración". Un hecho que se debió, como afirma el propio autor, a "que la compra de un receptor estaba muy alejada de las capacidades adquisitivas de la mayoría de las personas y que, hasta 1961, los televisores estuvieron gravados con un impuesto de lujo similar al que tenían las mercaderías más sofisticadas" (p. 316). 
La televisión llegó a ser, en un momento dado, el medio a través del cual se informaba la mayoría de la población española, muy por encima de la radio o la prensa. La televisión era el medio más influyente en la sociedad, no en vano el coste de la publicidad en televisión ha llegado a alcanzar cifras muy altas. Tan importante llegó a ser la televisión que los medios impresos no dudaron en imitarla, diseñando páginas cada vez más visuales, ligeras de texto escrito y llenas de imágenes y elementos tipográficos que llamaran la atención del lector.

Muchos periódicos utilizaban un lenguaje más simple, más directo, con frases más cortas o con voz activa, reflejando el estilo de redacción televisivo. Por esa razón, la responsabilidad de los periodistas a la hora de elaborar y transmitir las noticias fue en aumento y esta responsabilidad sigue siendo mayúscula con la aparición de nuevas formas de consumo y la democratización de las tecnologías.

En tiempos actuales, el aparato de televisión ya es lo de menos. Hay que preguntarse más por la conexión a Internet y la velocidad de la misma o por los diferentes dispositivos desde los que poder consumir información audiovisual. Quienes desean informarse sobre cualquier asunto solo deben disponer de un teléfono móvil conectado a Internet y acceder a las plataformas digitales de los medios que deseen. Ni tan siquiera necesitan saber cuál es la url que tienen que escribir en el buscador principal ya que, simplemente, con acudir a Google o cualquier otro buscador, pueden encontrar la información que quieran, retransmitida por el medio que deseen visionar. Como afirma Josep Monleón (2015) en un estudio del Grupo Prisa:

Las nuevas generaciones -y gran parte de la actual- no responden a un consumo reactivo, sino totalmente proactivo donde los usuarios ya no están dispuestos a que les fijes dónde, cómo y cuándo deben ver su programa, serie o película favorita ya que ellos son los que deciden todos estos parámetros (p. 14).

En los informativos en televisión, a lo largo de la historia ha habido cambios en cuanto a la forma y el formato. Para Rafael Díaz (2017) se ha ido pasando del "informativo de los bustos parlantes" al "de las noticias de cine", de ahí al "de las noticias electrónicas", luego vendría el "de las noticias en directo" para dar paso a "los informativos del espectáculo". Y añade: "uno no ha sustituido a otro sino que todo se ha ido haciendo más espectacular en unos casos y en otros simplemente se ha actualizado" (pp. 72-76).

En las últimas décadas el entretenimiento se ha convertido en el eje vertebrador de toda la programación audiovisual, también de los informativos. Como afirma Cebrián Herreros (2004), "la información en la televisión actual, en lugar de dar a conocer mejor el entorno al ciudadano, busca entretener, impactar, seducir al telespectador para que esté presente el mayor tiempo posible delante de la pantalla" (p. 12).

No obstante, todo ello también está cambiando debido a las nuevas formas de consumo de la información, en un momento en que el espectador quiere ver aquello que le interesa en el momento que le conviene y sin perder más tiempo del necesario para consumir aquello que desea.

Por tanto, se ha pasado de ver el informativo en un horario determinado a través del aparato receptor de televisión a poder consumir esa programación en cualquier momento del día desde un dispositivo conectado a Internet. Es lo que se conoce como noticias (en televisión) a la carta, que no deja de ser una nueva forma de consumo y sin que ello implique una nueva forma de hacer televisión. En este caso se trata de informativos a la carta, con la misma estructura que el informativo tradicional (con sus cambios a lo largo del tiempo) pero consumidos de una forma y en unos tiempos diferentes. Incluso, como señala Zamarra López (2010) en Internet se tiende a incluir vídeo en todo tipo de noticias, independientemente de si se trata de un medio tradicionalmente escrito, para "legitimar lo que dice" ese texto y para "contextualizar los acontecimientos que se refiere en la noticia o para mostrar un hecho difícil de describir" (p. 71). 
Actualmente, se denomina televisión a la carta o Video on Demand (VoD) a la posibilidad que tiene el consumidor de acceder a la programación de una cadena determinada cómo y cuándo lo desee. En España, la televisión a la carta es un servicio que, a día de hoy, ofrecen todas las cadenas de televisión públicas y privadas. No obstante, no todo el contenido de las cadenas es accesible VoD $\mathrm{y}$, del contenido accesible, no todo es gratuito, además de que, en algunos casos, el acceso a los contenidos es limitado en el tiempo. Hay que puntualizar que, normalmente, los archivos pueden visualizarse y descargarse, aunque dependiendo del medio es posible que a partir de un determinado momento éstos solo pueden visualizarse, pero no descargarse.

Otro aspecto importante es que no siempre se puede acceder a la televisión a la carta desde todos los lugares del mundo. Así, por ejemplo, si se quiere recuperar algún programa de la BBC no será posible si la IP desde la que se intenta acceder está registrada fuera de Reino Unido. A este respecto Salaverría (2019) sostiene que "aunque la trans-territorialidad de los medios en Internet se ha visto a veces restringida por razones jurídicas, todos los medios de comunicación son globales" (p. 7).

Para gestionar todos estos contenidos y, de paso, hacer negocio, han surgido plataformas tales como HBO o Netflix. Son plataformas de pago que surgieron en un primer momento como long tail, ofreciendo contenidos de otras cadenas y que actualmente ya están creando contenidos propios para su difusión a través de estas plataformas de pago.

Otra empresa referente en el mercado audiovisual es Amazon Video. Esta plataforma, que solo distribuía series y películas de producción externa, ha pasado a producir y distribuir contenidos de producción propia. Amazon, se convierte así, en una de las plataformas que más rendimiento le está sacando a Internet y rentabilizando todas sus posibilidades en cuanto a modelo de negocio; una plataforma a la que el usuario se suscribe (Amazon Prime) y por el mismo precio puede comprar por Internet de forma segura y sin gastos de envío, a la vez que disfruta de las ventajas de Amazon Video, de forma que el consumidor está pagando por el servicio un precio muy bajo que, multiplicado por millones de personas, crea un gran volumen de negocio para esta multinacional.

Según algunos investigadores, Amazon es una de las empresas que dominan Internet (a día de hoy) junto a Google, Facebook, Apple y Microsoft. Natalia Zuazo (2018) las denomina "El Club de los Cinco, un manojo de corporaciones que concentra tanto poder que gran parte de la economía, la sociedad y las decisiones del futuro pasan por ellas" (p. 5). Para la autora "Google lidera las búsquedas, la publicidad y el aprendizaje automatizado. Facebook controla gran parte del mercado de las noticias y la información. Amazon, el comercio en gran parte de Occidente, y está avanzando en producir y distribuir también sus propios productos”. (p. 7)

En 2019, otra gran multinacional del audiovisual inició su expansión en el negocio de la televisión a la carta. Es el caso de Disney+, empresa que el 12 de noviembre de 2019 ya estaba disponible en Estados Unidos y, en España, comenzó su operatividad a partir del 22 de marzo de 2020. Si bien podríamos pensar que Disney+ no es más que una plataforma para difundir películas y series de televisión, esta plataforma lleva asociadas otras como ESPN+, que según publica Raya (2019) en el diario digital elespanol.com, es "el servicio de streaming deportivo más popular de EE.UU., ofreciendo partidos en directo de la liga profesional de béisbol, fútbol, y hockey sobre hielo; además de acceso a su programación habitual sobre fútbol americano y otros deportes" (párr. 6).

En el contexto actual, Estados Unidos va muy por delante en lo que a televisión a la carta se refiere. Todo ello significa que cualquier ciudadano estadounidense, independientemente de su nivel económico o su procedencia tiene asimilado que debe emplear una parte de sus ingresos a pagar por ver la televisión. Una peculiaridad importante en la programación de las cadenas estadounidenses es que muchas de ellas emiten programación en español, debido a la gran cantidad de hispanohablantes que viven en el país. 
En este punto hibridan comunicación y grandes compañías distribuidoras de información a través de Internet. Por tanto, es conveniente y pertinente hablar del consumo de información a través de la multiplataforma.

\subsection{Multiplataforma: el presente de la televisión}

Si en 2011 algunos autores hablaban del sistema multiplataforma como "el futuro audiovisual" (Liendo y Servent, 2011, p. 202), en 2020, se puede hablar ya del presente de la televisión y del periodismo audiovisual consumido a través de múltiples plataformas. Para discutir de la información en el entorno multiplataforma, es necesario determinar qué es la multiplataforma. Entendemos la multiplataforma en cuanto a los diferentes dispositivos en los que se puede recibir la información audiovisual, pero también los diferentes formatos en los que puede ser elaborada y difundida esta información.

Liendo y Servent (2011), en relación a la "Producción Multiplataforma", sostienen que "Se refiere a la creación de productos audiovisuales que logran una alta eficacia comunicativa en diversas pantallas, considerando y aprovechando las características propias de cada una y que brindan una alta experiencia de usuario por cualquier camino de acceso" (p. 203). También hacen referencia a otras plataformas "Plataformas de Videojuegos (...) Dispositivos ópticos, DVD y Blue-Ray (...) Plataformas desde las formas del relato". Afirman además, que el proceso multimedia consiste "en producir para televisión en alta definición y convertirlo para las diversas plataformas. Es decir, de una secuencia de tomas se obtiene un producto final, a ese producto se lo convierte a distintas plataformas" (p. 203-209).

Actualmente, en España, se está haciendo este tipo de proceso multimedia. Se elabora un producto con unas determinadas características y el mismo producto intenta adaptarse a las diferentes plataformas, tanto en lo referente a los formatos como a las pantallas. Por consiguiente, una información elaborada en HD o SD se adapta para ser difundida a través de las redes sociales, de Youtube, de la Televisión Digital Terrestre, de las APP de los teléfonos móviles y tabletas y cualquier otro formato o pantalla a través de la cual puede consumirse la información. No se elaboran productos diferentes para formatos diversos, sino que se intentan optimizar los recursos produciendo formatos que puedan adaptarse a cualquier forma de consumo.

\subsection{Del informativo a la carta al vodcasting informativo}

En el avance y evolución del nuevo ecosistema de la información audiovisual, en España, el informativo a la carta es ya una realidad. El espectador no tiene que correr hacia el receptor de televisión a la hora indicada para ver lo que cualquier cadena televisiva ha considerado como noticia y cómo va a contársela. El ciudadano que desee visionar un informativo solo tiene que conectarse al medio en cuestión, ir a televisión a la carta y visionar ese programa que desea consumir; sin horarios (más allá de la información que desee visionar en directo). Por tanto, como afirma Pavlik (2005):

El público ya no es pasivo; ha cobrado vida con la actividad. La gente puede obtener su información de, literalmente, miles de fuentes de todo el mundo. Podemos tener la noticia desde diferentes perspectivas, situada en un rico contexto histórico, y contada con una gran diversidad de modalidades comunicativas, no sólo una o dos, que era lo que permitían los medios analógicos. Por ejemplo, el audio, el vídeo, la interactividad, las imágenes inmersivas y navegables, el texto, los hiperenlaces y muchas más cosas se pueden conseguir en la red (pp. 64-65).

La televisión a la carta no es más que la posibilidad de ver "programas o fragmentos" de los que ya se ha emitido a través de la televisión convencional o cualquier otro dispositivo conectado a Internet en el momento en que el usuario tenga tiempo para recuperar esa información (Díaz, 2017, p. 89). 
En esta línea, el avance es importante desde el punto de vista del consumidor, pero no es suficiente con las grandes oportunidades que Internet abre en este sentido.

Podemos definir el vodcast como la tecnología que da la posibilidad de ver o tener acceso a videos por Internet, es la abreviación de video + podcast. El Video podcast o podcast de video o, simplemente, vodcast es utilizado para la entrega en línea de un videoclip a demanda desde un canal RSS o plataformas como Youtube o Twich, entre otras. Muchos consideran que el término es redundante y que el término podcast es suficiente pues encierra los formatos de audio y video. Como afirman Spinelli y Dann $(2019$, p. 7) sobre los podcasts, los vodcast se mueven con el cuerpo humano y son consumidos en espacios urbanos, mientras se transita, en las calles y en otros espacios públicos. Sin embargo, el término podcasting es utilizado para el audio mientras que el vodcasting lo hace para el vídeo. No obstante, son fenómenos que están adquiriendo gran relevancia en el ámbito mediático actual.

Por todo esto, un paso más allá de la televisión a la carta se sitúa el podcasting de vídeo o vodcasting. El vodcasting es un producto elaborado para ser consumido única y exclusivamente a través de Internet. Según Pascual (2019) podemos decir que los podcasts de vídeo "suelen utilizar el formato MP4, o el m4v" (p.7). Junto al vodcast surge una variante conocida como screencast, término que este autor describe como "una variante del podcast de vídeo en donde se muestra la pantalla del ordenador para enseñar a manejar una aplicación, o completar una tarea. Suele utilizarse en tutoriales y cursos" (p.7).

En España, según un artículo publicado en 2006, por la Agencia Europa Press, la primera serie de TV distribuida mediante videopodcast en iTunes y Apple, fue, 'Emprendedores' (2 de TVE). En el artículo se afirma:

Todos los capítulos de la serie 'Emprendedores', que La 2 emite los lunes y miércoles a las 21 horas, pueden descargarse de Internet de forma gratuita en formato videopodcast iTunes de Apple, en la que supone la primera iniciativa de esta forma de distribución para una serie de televisión en España (párr. 1).

Si bien es cierto que este formato de distribución de información está creciendo en diversos países europeos, estadounidenses, asiáticos y latinoamericanos, como sostiene Richard Berry $(2019$, p. 1), a pesar de que los vodcasts forman parte del mismo ecosistema que los podcasts, es un espacio en el que el audio es la fuerza dominante. En España, está en auge el podcasting (en el caso de la radio), mientras que el vodcasting o podcasts de vídeo es aún embrionario. De hecho, el término vodcasting no está implementado en las webs de las cadenas de televisión convencionales españolas, como sí ocurre en el caso de la radio con el podcasting. Todo ello significa que las cadenas de televisión españolas no han acuñado el término vodcasting, ni siquiera para referirse a la televisión a la carta, como sí lo hacen varias emisoras de radio con la radio a la carta, a la que llaman podcasting (Moreno y Román, 2020).

Como decimos, en otros países no ha ocurrido lo mismo. Así, por ejemplo, la británica BBC asegura que sí hace video podcasting y lo diferencia del iPlayer de la BBC que sería la televisión a la carta, simplemente porque estos contenidos se pueden descargar y visionarlos sin conexión. En realidad, es televisión a la carta la que se puede descargar, puesto que no es un contenido pensado, diseñado, elaborado y distribuido como un nuevo producto, sino fruto de otro que ya se ha emitido por la televisión convencional.

No obstante, hoy se está denominando vodcasting, podcasting de video o vlogging al contenido que aúna audio y vídeo y que puede ser descargado (Clapperton, 2010) desde cualquier página web o a través de la suscripción, en cualquiera de los programas disponibles para ello, para ser visionado bien en el momento o bien cuando el usuario lo desee. En el ámbito audiovisual solo algunas empresas han implantado los vodcast, como es el caso de Euro Sport con 'La casa del ciclismo' o más 
recientemente 'Confinados', un programa que surgió como vodcast durante la pandemia provocada por la COVID-19 en 2020 y que posteriormente se convirtió en un programa de televisión.

En España, donde más vodcast informativos existen es, curiosamente, en los diarios de prensa, así por ejemplo, el Diario $A B C$, en su página web tiene un apartado en el menú que se llama vídeo, donde se pueden visionar vodcast elaborados expresamente para ser visionados a través de Internet. Uno de ellos es ABCSALUD, pero los hay de todos los temas de actualidad. No es sencillo encontrarlos y tampoco es fácil descargar los vídeos que están en la url: https://www.abc.es/multimedia/ videos/

Otros periódicos en su edición online también ofrecen la posibilidad de ver vídeos, pero lo que diferencia los vídeos de $A B C$ de los de El País, por ejemplo, es que los vídeos de $A B C$ están locutados y en El País simplemente son entrevistas de otros medios, como la Cadena Ser, avances de películas, declaraciones textuales o imágenes con sonido ambiente.

Asimismo, el diario El Mundo tiene algunos vodcast de opinión en su página web, pero normalmente son vídeos como los que emite el diario El País. Otro medio que ofrece vodcast sobre información general es La Vanguardia, que no tiene en el menú una pestaña para vídeo, pero sí los tiene elaborados acompañando a cierta información escrita de actualidad. No obstante, La Vanguardia también tiene vídeos que se limitan a reproducir sonido ambiente, declaraciones, etc., al igual que el resto de los medios.

El vodcasting informativo no está plenamente desarrollado como sí lo está la información televisiva a la carta. Un vodcast que esté elaborado como nuevo producto informativo debe tener entidad por sí mismo, al igual que sucede con el podcasting, creando un nuevo "nuevo periodismo" (Spinelli y Dann, 2019, p. 2). Así, el vodcast debe identificar la fecha y hora en que se ha elaborado esa información, así como los profesionales que la han elaborado.

Elementos que no estarían de más en un vodcast serían la identificación de todas las fuentes a las que se ha recurrido para elaborar la información, así como un análisis pormenorizado de todos los puntos de vista sobre el asunto a tratar.

Un gran ejemplo sería 5W que elabora su información a través de podcasting (solo audio). Los periodistas de este medio hacen información, análisis, entrevistas, reportajes, etc., dando respuesta a las denominadas 5w del periodismo: quién, qué, cuándo, dónde y por qué. En los podcasts los periodistas van respondiendo a cada una de estas preguntas recurriendo a diversas fuentes que ofrecen diferentes puntos de vista sobre un mismo tema. Dichos podcasts duran aproximadamente una hora y son muy completos. Si este formato se pasara a vídeo, la información sería aún más completa, aunque necesitarían más medios para su difusión.

Precisamente, ahí radica la complejidad del vodcasting frente al podcasting. Mientras que para hacer podcasting solo es necesario un dispositivo conectado a Internet con una entrada de audio, para el vodcasting es necesario registrar también imágenes que tienen que sincronizarse con el audio y otros grafismos, con lo cual ya se necesitan al menos dos tecnologías cuando no programas de edición para elaborar la información y además hacerla atractiva.

En el entorno audiovisual, la redacción tiene que estar adaptada al formato y, más allá del sonido, la imagen juega un papel fundamental en cualquier pieza informativa para ser vista y oída. La imagen debe ser cuidada y mimada al detalle, una peculiaridad que, últimamente, se está teniendo muy poco en cuenta en diferentes programas de información tipo magazín e incluso en los propios informativos donde, a menudo, se presentan al espectador imágenes de mala calidad, tomadas con un teléfono móvil por cualquier ciudadano, con más buena intención que criterio periodístico (Román, 2019, p. 925). 
Es cierto que hay casos en los que puede primar la necesidad de información a la calidad de la imagen, pero cuando esto se vuelve una costumbre puede empobrecer sobremanera el producto periodístico.

Por otro lado, la televisión y por extensión el vodcasting, son una realidad multidimensional en la que la imagen, los gráficos, el texto, el hipertexto y el sonido se hibridan para ofrecer información más completa, de mejor calidad, más contrastada y, en definitiva, más atractiva para la audiencia.

Por todo ello, la tarea del profesional de la información en los medios audiovisuales no resulta fácil, pues constantemente entran en juego la capacidad intelectual y las convicciones éticas del periodista que se enfrenta a la información con una serie de condicionantes que, en ocasiones, dificultan en demasía su trabajo.

Hasta ahora, parecía que el mayor reto al que se enfrentaba el periodista era a la adaptación a las nuevas tecnologías para ser capaz de hacer un uso eficiente de ellas, ahora tiene que ir más allá para no solo saber manejar las nuevas herramientas de trabajo, sino hacerlo con honestidad y profesionalidad, superando el "todo vale" en la información periodística y desmintiendo incluso bulos o fake news, puesto que el principio de veracidad "debe acompañar no solo a las organizaciones de noticias, sino, también, a los profesionales de la información que, individual o colectivamente, se dedican a la creación y difusión de noticias" (Flores, 2019, p. 198).

Si la idea básica del periodismo televisivo es acercar a los espectadores información lo más próxima posible a la realidad, en la era del vodcasting los postulados profesionales no deben variar, tan solo las formas de elaborar la información y de hacerla llegar a los consumidores.

\section{Resultados}

Desde hace varios años se viene hablando de conceptos como Videoperiodismo (Pätzold, 2005; Román, 2009; Franco, 2011; Álvarez, 2017), concepto que surgió a finales de la década de los noventa y no implicaba la difusión inmediata o el MOJO (Quinn, 2009; Westlund, 2013; Blankenship, 2015; Crespo, 2016; Burum y Quinn, 2016; López-García et. al., 2019; Perreault y Stanfield, 2019), que hace referencia al periodismo móvil, aquel que puede realizarse en cualquier momento gracias a las posibilidades que ofrecen los dispositivos digitales e Internet.

Sobre el MOJO (acrónimo de Mobile Journalism), en la encuesta realizada para este trabajo a directivos y responsables de informativos, los profesionales respondieron coincidiendo en que estaban de acuerdo en que quizá adelgazaría las redacciones de los medios audiovisuales, a la vez que se planteaban la pérdida de calidad de los procesos de elaboración. Alguno de ellos destacaba las posibilidades que ofrece para posibilitar la inmediatez informativa en lugares de difícil acceso. Como sostiene Salaverría (2018) "En pocos años, hemos pasado de buscar noticias a sentirnos desbordados por la información" (p. 16). Si en el siglo XX eran los anuncios publicitarios los que invadían a la ciudadanía cada vez que ponía el pie en la calle, compraba el periódico o encendía el televisor o el transistor, en los inicios del siglo XXI Internet ha hecho, a través del teléfono móvil, que se reciba multitud de información, en forma de reclamo publicitario o no, que los usuarios consumen a diario sin quererlo y, a veces, sin tan siquiera ser conscientes de ello.

En la Era Digital, la información ha ido adaptándose a los nuevos gustos y formas de consumo. Los expertos han venido alertando sobre estos cambios y transformaciones. Así, Cebrián Herreros (2004) advertía que "hay una tendencia clara a limitar la duración de cada noticia en torno al minuto, algo insuficiente para la comprensión del hecho" (p. 117); un punto que corroboran algunos de los directivos de informativos testados en la presente investigación, quienes sostienen que los datos de consumo marcan los formatos, su elaboración y estructura. Los informativos se han redefinido 
tanto en contenidos, como formatos y duración de las noticias. Consecuentemente, los relatos se hacen en función de los soportes, y la importancia de la imagen en tabletas y teléfonos móviles es evidente.

Esto es lo que afirman los directivos y responsables de informativos de Canal Sur Televisión y la delegación territorial de TVE en Andalucía, en la encuesta realizada para este trabajo en diciembre de 2019, quienes respondieron, en algunos casos, identificando sus nombres y apellidos y filiación, y en otros, de forma anónima.

Paloma Jara, directora del Centro Territorial de RTVE en Andalucía, sostiene al respecto que:

Las nuevas narrativas están ya aquí y tienen que ver con este nuevo consumo de la información. Un ejemplo lo encontramos en las piezas audiovisuales que ya se generan específicamente para consumo en redes y que vienen acompañadas por un diseño muy cuidado en cuanto a grafismo, infografía e incluso ritmo, con planos más picados y tendentes a captar la atención del espectador. Y algunas de esas piezas se empiezan a incluir en los espacios informativos tradicionales, aunque no hayan sido concebidas para este formato, sino para el tráfico en redes.

Rafael Adamuz, director de la RTVA en Huelva, cree que "se ha impuesto ya una nueva forma que requeriría un análisis pormenorizado más detenido y prolijo", a lo que añade que sí aprecia "adaptaciones en determinados informativos con recursos ad hoc para ello. Pero aún falta más".

Entonces, ¿hacia dónde se dirige el periodismo audiovisual? Los directivos y responsables de informativos son claros en este aspecto. Paloma Jara afirma que el periodismo audiovisual "en la actualidad va hacia la inmediatez, el espectáculo y los formatos flash, especialmente en lo referente a los informativos donde vemos cómo se incluyen parte de las nuevas narrativas y tendencias que ya imperan en las redes sociales y entornos interactivos." Todo esto en cuanto al cómo, pero, en cuanto a la forma, sostiene que "tiene que ir ahora hacia donde debe haber ido siempre: a formar ciudadanos críticos, informados de forma rigurosa y honesta. A construir, en definitiva, Democracia". Y por ello afirma que junto al flash nos encontramos "otros formatos también informativos, pero más cuidados y específicos, creados para el tráfico en determinadas plataformas a los que acceden los consumidores para recibir una información más trabajada y reflexiva". En esta misma línea, Adamuz, opina que el periodismo audiovisual se encamina:

Hacia un cambio constante en los formatos y en consonancia con la evolución de las nuevas tecnologías y los nuevos conceptos de consumo. Su estructura, sus métodos de trabajo, su organización... se verá supeditada a todo ello. Será determinante, también, el grado de independencia de estos en función de sus propietarios/inversores. Habría que distinguir aquí entre medios públicos y privados.

También es importante la opinión de los directivos de informativos respecto al efecto que el entorno multiplataforma tiene en la creación y difusión de la información audiovisual. Adamuz considera el entorno multiplataforma como "una posibilidad de explotar las posibilidades de creación y difusión, la búsqueda de nuevas formas de narrar audiovisualmente, estilos, formatos, temáticas, audiencias..." En una línea contrapuesta, una responsable del ente público andaluz (que no ha querido desvelar su identidad) afirma que "en la actualidad ya no se concibe la creación y difusión de la información audiovisual sin un entorno multiplataforma. Lo contrario es estar fuera de mercado. Por tanto, cualquier contenido se ha de ajustar a las reglas del proyecto multimedia".

Pero, la televisión, como cualquier medio de comunicación, es un modelo de empresa; y para la empresa, los beneficios son su razón de ser. En este sentido, el reto está en cómo medir la audiencia $\mathrm{y}$ atraer mayores ingresos publicitarios como mecanismo para seguir sobreviviendo en el mercado.

Numerosas empresas de análisis de audiencias se han lanzado a lo que se conoce como la métrica de la audiencia agregada donde se tiene en cuenta el directo, el diferido y la cross-platform que es 
lo que en España conocemos como la multiplataforma (Kantar Media, 2019). De hecho, Amazon ya trabaja en esta línea. No en vano, es uno de los gigantes que controla Internet y la televisión multiplataforma. En este sentido, Conrad Riggs, en MIPTV (considerada la mayor feria del audiovisual), indica que en Amazon Prime Originals: "se están centrando 'en satisfacer la creciente demanda de programas de telerrealidad"” (EFE, 2017). Un ejemplo es el documental que Amazon emitió en septiembre de 2019, a través de la plataforma Amazon Prime sobre el futbolista Sergio Ramos, donde abordaba tanto aspectos de su trayectoria deportiva como de su vida profesional. Mucho se habló de la financiación de esta multinacional de la mediática boda del futbolista con la periodista Pilar Rubio en el verano de 2019, en Sevilla, a la que asistieron un gran número de famosos y famosas.

Otro concepto ligado a la televisión online a través de las SMARTV es lo que autores como Díaz (2017) han venido a denominar el hybrid broadcast broadband TV (HbbTV) que "aporta interactividad selectiva (VoD), dialógica (se pueden responder encuestas, votar, comentar) y una limitada interactividad narrativa en la medida en que se puede seleccionar un punto de vista de un acontecimiento retransmitido en directo" (p. 92).

En pocos años se ha pasado del informativo en televisión a la información a la carta, una forma de consumo informativo que ya no está fijado en una fecha y hora concretas a través de un único dispositivo, sino una información que se consume en plataformas múltiples, en momentos diversos y de una forma no lineal. Pero de ahí, el salto debe ser hacia el vodcasting, nuevos formatos de informativos audiovisuales diseñados y elaborados en exclusiva para ser consumido online, independientemente de la pantalla que nos posibilite su visionado.

Pese a que los directivos en las encuestas no mencionan expresamente el vodcasting que, como se vio en apartados anteriores, está poco implementado en nuestro país, si abogan por unas formas de consumo informativo más adaptadas a las necesidades de cada usuario gracias a las posibilidades que ofrecen dispositivos cada vez más fáciles de manejar, más ligeros y con una velocidad de conexión a Internet más rápida. Y estas nuevas narrativas que defienden los directivos encuestados y estos nuevos productos informativos adaptados a los nuevos consumidores pasan por lo que se conoce como podcasting de vídeo, video podcast, VoD o vodcasting.

\section{Discusión y conclusiones}

Un producto genuinamente multiplataforma debería estar diseñado de tal forma que consiga sacar el máximo partido a cualquier formato, aplicación, pantalla, plataforma, etc. Se trataría de un producto que el receptor logre, no solo recibir a través de cualquier medio, sino sobre el que también pueda opinar, si la plataforma se lo permite, e incluso añadirle información, corregir erratas o aportar un análisis personal de la información.

La televisión a la carta es una realidad que se adapta a cualquier dispositivo de visionado, así como a diferentes plataformas de contenidos audiovisuales. Ahora el reto está en crear contenidos propios para ser difundidos en esas plataformas a través de vodcast sin depender de la televisión convencional. Esto es algo que ya están haciendo varios diarios que tienen su origen en la información escrita, quizá por aportar a la información el carácter visual que adquirieron las publicaciones impresas con la llegada de la televisión y al que ahora se puede poner también voz e imagen en movimiento.

El vodcasting es aún embrionario en España, aunque ya hay proyectos muy interesantes, con numerosos seguidores y que están generando un nuevo negocio en el sector audiovisual. Es un nuevo formato con el que transmitir información de una manera fresca, sin perder el rigor de la información periodística de calidad, pero con la capacidad de llegar a una audiencia más diversa. Un ejemplo podría ser Historias de Luz, en el ámbito andaluz o, más recientemente, 'Confinados' en Eurosport. 
El fenómeno vodcasting supone una nueva forma de llegar a una audiencia más amplia a través de Internet, con información audiovisual de calidad, que genera un producto para ser consumido más allá de la propia Web.

A diferencia del podcasting, que ya está bastante extendido en España, el vodcasting requiere unos medios técnicos específicos para generar un buen producto audiovisual, mucho más exigente que el producto radiofónico. Quizá sea este hecho lo que está haciendo que no proliferen tanto estos productos en los que prima la imagen, como sí lo están haciendo los radiofónicos.

En referencia a los profesionales de la información, el papel del periodista deberá seguir siendo fundamental en la recopilación, selección, elaboración y difusión de información de calidad. Son profesionales que recurren a las fuentes oportunas para evitar las actuales fake news, que tan fácilmente se pueden elaborar y difundir, sobre todo, a través de las redes sociales. Junto a ellos, quizá sería oportuno el trabajo de técnicos especialistas en la captación y edición de la imagen, para un producto de alta calidad. No obstante, ya existen programas informáticos intuitivos para agilizar la edición de imagen con resultados muy buenos.

Por tanto, Internet, y las grandes posibilidades que crea en la distribución de contenidos no cambiará la esencia del trabajo de los periodistas; cambiarán los formatos y los lenguajes, pero no la búsqueda de la veracidad, el rigor y la pluralidad, señas de identidad de la información periodística de calidad.

El vodcasting es un gran formato para mantener la calidad y el rigor informativo a la vez que los informativos en televisión son capaces de llegar a grupos de población más joven y con unas formas de consumo que difieren de las que se venían dando hasta ahora.

\section{Bibliografía}

Álvarez, D. (2017). Videoperiodismo Digital: claves para la transición desde el periodismo tradicional en Escudero Nahón, A.y González Calderón, D. Escenarios y desafíos de la comunicación y la cultura en el espacio audiovisual iberoamericano. Universidad Internacional de Andalucía. https://url2.cl/qVcyE

Asociación para la Investigación de Medios de Comunicación (2021). Penetración de la televisión por target. $A I M C$. https://reporting.aimc.es/index.html\#/main/television

Asociación para la Investigación de Medios de Comunicación (2021). Penetración de Internet por target. AIMC. https://reporting.aimc.es/index.html\#/main/internet

Barlovento Comunicación (2020). Balance del consumo de televisión durante el Estado de Alarma (del 14 de marzo al 20 de junio de 2020). https://url2.cl/QT7yC

Berry, R. (2019). Podcasts and Vodcasts in Vos, T.P. and Hanusch, F. (eds.). The International Encyclopedia of Journalism Studies (Vol. 1, pp. 1-5). Wiley. https://doi. org/10.1002/9781118841570.iejs0182

Blankenship, J. (2015). LOSING THEIR “MOJO”? Mobile journalism and the deprofessionalization of television news work. Journalism Practice, 10(8), 1055-1071. https://doi. org/10.1080/17512786.2015.1063080

Brown, A. and Green, T.D. (2007). Video Podcasting in Perspective: The History, Technology, Aesthetics, and Instructional Uses of a New Medium. Journal of Educational Technology Systems, 36(1), 3-17. https://doi.org/10.2190\%2FET.36.1.b 
Burum, I. y Quinn, S. (2016). MOJO: the mobile journalism handbook. How to make broadcast videos with an iPhone or iPad. Taylor \& Francis Group.

Cann, A.J. (2007). Podcasting is Dead. Long Live video! Bioscience Education, 10(1), 1-4. https:// doi.org/10.3108/beej.10.c1

Casero-Ripollés, A. (2012). Más allá de los diarios: el consumo de noticias de los jóvenes en la era digital. Comunicar, XX (39), 151-158.

Cebrián Herreros, M. (2004). La información en televisión: Obsesión mercantil y politica. Gedisa.

Clapperton, G. (9 de septiembre de 2010). What is podcasting and vodcasting?. BBC. http://www. bbc.co.uk/webwise/guides/podcasting-vodcasting

Crespo, E. (3 de junio de 2016). Llega el \#mojo, el periodismo móvil. RTVE. https://www.rtve.es/ rtve/20160603/llega-mojo-periodismo-movil/1354831.shtml

Díaz, R. (2017). La información periodística en televisión. Síntesis.

Dirección de Comunicación y Marketing Corporativo de PRISA (2015). Los medios en 2020: Así serán la prensa, la radio y la televisión. Prisa.

Dupagne, M.; Millette, D. and Grinfeder, K. (2009). Effectiveness of Video Podcast Use as a Revision Tool. Journalism and Mass Communication Educator. 64(1), 54-70. https://doi. org/10.1177\%2F107769580906400105

Europa Press (2006). 'Emprendedores' (La 2), la primera serie de TV distribuida en España mediante videopodcast en iTunes de Apple. Europa Press. https://www.europapress.es/ nacional/noticia-emprendedores-primera-serie-tv-distribuida-espana-videopodcast-itunesapple-20060130145414.html

Flores-Vivar, J. (2019). Inteligencia artificial y periodismo: diluyendo el impacto de la desinformación y las noticias falsas a través de los bots. Doxa Comunicación, (29), 197-212. https://doi.org/10.31921/doxacom.n29a10

Franco, C. (2011). Herramientas de vídeo-periodismo, ante la disyuntiva calidad e inmediatez, TecCom Studies. Estudios de tecnología y comunicación, núm. 1, año 1, 103-108. http://www. teccomstudies.com/index.php?journal=teccomstudies\&page $=$ article\&op=view\&path $\% 5 \mathrm{~B} \%$ $5 \mathrm{D}=144 \&$ path $\% 5 \mathrm{~B} \% 5 \mathrm{D}=124$

García-Marín, D. (2019). La radio en pijama. Origen, evolución y ecosistema del podcasting español. Estudios sobre el Mensaje Periodístico, 25(1), 181-196. http://dx.doi.org/10.5209/ESMP.63723

Geoghegan, M.W. and Klass, D. (2007). Podcast Solutions: The Complete Guide to Audio and Video Podcasting. Friendsof. Scond Edition.

INE-Instituto Nacional de Estadística (datos de 2018). https://www.ine.es/prensa/tich 2018.pdf

INE-Instituto Nacional de Estadística (datos de 2020). Encuesta sobre el equipamiento y uso de tecnologías de información y comunicación en los hogares. Resultados. INE. https://www.ine.es/ dyngs/INEbase/es/operacion.htm?c=Estadistica_C\&cid $=1254736176741 \&$ menu=resultados\&i$\underline{\mathrm{dp}}=1254735976608$

INE-Instituto Nacional de Estadística (datos de 2020). Evolución de datos de Viviendas (20062020) por tamaño del hogar, hábitat, tipo de equipamiento y periodo. INE. https://www.ine.es/jaxi/ Datos.htm?tpx $=39397$ 
INE-Instituto Nacional de Estadística (datos de 2020). Uso de dispositivos o sistemas conectados a Internet, con fines privados en el hogar, por características demográficas y tipo de dispositivo. $I N E$. https://www.ine.es/jaxi/Datos.htm?tpx=39462\#!tabs-tabla

Juste, M. y Galera, C. (23 de marzo de 2020). El consumo de televisión en España bate su récord histórico en la primera semana de confinamiento. Expansión. https://www.expansion. com/economia-digital/2020/03/23/5e 74e31a468aeb92708b45d3.html\#: :text=El\%20primer\%20 domingo $\% 20 \mathrm{de} \% 20$ confinamiento, datos $\% 20 \mathrm{de} \% 20 \mathrm{TV} \% 20 \mathrm{desde} \% 201992$ )

Kantar Media (2019). Cross-media: medición conjunta de la audiencia en TV e Internet. https:// www.kantarmedia.com/es/soluciones/medicion-de-audiencias/cross-media

Legorburu, J.; Edo, C. y García González, A. (2021). Reportaje sonoro y podcasting, el despertar de un género durmiente en España. El caso de Podium Podcast. Estudios Sobre El Mensaje Periodístico. 27(2), 519-529. https://doi.org/10.5209/esmp.71204

Liendo, C.G y Servent, P.A. (2011). Pensar para la producción audiovisual multiplataforma para la Televisión Digital. Pangea. Revista de la Red Académica Iberoamericana de Comunicación, año 1, artículo núm. 10, 199-213. https://dialnet.unirioja.es/servlet/articulo?codigo=4005036

López-García, X.; Silva-Rodríguez, A.; Vizoso-García, Á.; Westlund, O. y Cavanilhas, J. (2019). Mobile journalism: Systematic literatura Review. Comunicar, XXVII(59), 9-18. https://doi. org/10.3916/C59-2019-01

López-García, X. y Vizoso, Á. (2021). Periodismo de alta tecnología: signo de los tiempos digitales del tercer milenio. Profesional de la información, 30(3), 1-12. https://doi.org/10.3145/epi.2021.may.01

Moreno Cazalla, L. (2017). Podium podcast, cuando el podcasting tiene acento español. Prisma Social. (18), 334-364. https://revistaprismasocial.es/article/view/1418

Moreno Espinosa, P. y Román San Miguel, A. (2020). Podcasting y periodismo. Del periodismo radiofónico de inmediatez a la información radiofónica de calidad. Estudios Sobre El Mensaje Periodístico, 26(1), 241-252. https://doi.org/10.5209/esmp.67303

Pagadigorria Ruíz, A.; Iglesias Chaves, A.; Etxebarria Lejarreta, A. y Romero Andonegi, A. (2017). El podcast de vídeo: la motivación como elemento de interactuación entre alumnado universitario de los grados de ciencias y comunicación audiovisual. [IV Congreso Internacional sobre Aprendizaje, Innovación y Competitividad (CINAIC 2017)], págs. 424-427. https://zaguan. unizar.es/record/62924/files/089.pdf

Palacio Arranz, M. (2006). Cincuenta años de televisión en España en Díaz Nosty, B. y Fernández Beaumont, J. Tendencias 06. Medios de Comunicación. El año de la televisión (pp. 315-319). Fundación Telefónica. https://dialnet.unirioja.es/servlet/articulo?codigo $=4990892$

Parson, V.; Reddy, P.; Wood, J. and Senior, C. (2009). Educating an iPod generation: undergraduate attitudes, experiences and understanding of vodcast and podcast use, Learning. Media and Technology. 34(3), 215-228. https://doi.org/10.1080/17439880903141497

Pascual Estapé, J. (2019). El podcasting en España: de espejo de las radios a formato de éxito. Computer Hoy. https://computerhoy.com/reportajes/entretenimiento/podcasting-espana-espejoradios-formato-exito-351773

Pätzold, U. (2005). Chancen und Grenzen des Videojournalismus mit besonderem Schwerpunkt auf der permanenten Auslandsberichterstattung, Markus Böhnisch. http://boehnisch.social-mediauniversum.de/wp-content/uploads/2010/06/videojournalismus2-0.pdf 
Pavlik, J.V. (2005). El Periodismo y los nuevos medios de comunicación. Paidós.

Perreault, G. y Stanfield, K. (2019). Mobile Journalism as Lifestyle Journalism? Journalism Practice, 13(3), 331-348. https://doi.org/10.1080/17512786.2018.1424021

Quinn, S. (2009). MoJo-Mobile Journalism in the Asian Region. Singapore: Konrad Adenauer Stiftung. https://azargh.farhang.gov.ir/ershad_content/Media/image/2012/02/175366_orig.pdf

Raya, A. (7 de agosto de 2019). Disney lanza un ataque nuclear contra Netflix: deportes, series y Disney+ juntos. El Español. https://www.elespanol.com/omicrono/20190807/disney-ataquenuclear-netflix-deportes-series-juntos/419708192 0.html

Román, A. (2009). Nuevas formas de hacer periodismo: los videoperiodistas en Marzal Felici, J.; Casero Ripollés, A.; Gómez Tarín, J. Tendencias del periodismo audiovisual en la era del espectáculo. III Congreso Internacional de Teoría y Técnica de los Medios Audiovisuales. Universitat Jaume I. https://core.ac.uk/download/pdf/61399811.pdf

Román San Miguel, A. (2019). Las redes sociales como fuente de información en el periodismo en televisión en De Vicente Domínguez, A.M. y Sierra Sánchez, J. Aproximación periodística y educomunicativa al fenómeno de las redes sociales (921-930). McGraw Hill.

Ruano, S. (2009). Internet y la telefonía móvil nuevos soportes para distribuir contenidos audiovisuales, Razón y Palabra, 14(68). www.razonypalabra.org.mx/N/n68/varia/ruano.html

Salaverría, R. (2018). Del periodismo móvil al obicuo. Allá donde estés, habrá noticias.

Cuadernos de periodistas. (35). http://www.cuadernosdeperiodistas.com/alla-donde-estes-habranoticias/

Salaverría, R. (2019). Digital journalism: 25 years of research. Review article. El profesional de la información, 28(1), 1-26. https://doi.org/10.3145/epi.2019.ene.01

Spinelli, M. and Dann, L. (2019): Podcasting. The Audio Media Revolution. Bloomsburi Academic.

Statista (2018). Evolución del porcentaje de hogares con televisores inteligentes conectados a Internet en España entre 2013 y 2018. Statista. https://es.statista.com/estadisticas/508168/ porcentaje-de-hogares-con-smart-tv-contectado-a-internet-en-espana/

Westlund, O. (2013). A review and model of journalism in an age of mobile media. Digital Journalism, 1(1), 6-26. https://www.tandfonline.com/doi/pdf/10.1080/21670811.2012.740273?needAccess $=$ true

Zamarra López, M. (2010). El uso del audio y del vídeo en los ciberperiódicos en Cebrián Herreros, M. (coord.). Desarrollos del Periodismo en Internet (pp. 65-79). Comunicación Social.

Zuazo, N. (2018) Los dueños de internet. Cómo nos dominan los gigantes de la tecnología y qué hacer para cambiarlo. Debate. 